\title{
STUDIES ON VARIABILITY IN Alternaria alternata (KESSLER) CAUSING LEAF BLIGHT OF ISABGOL (Plantago ovata)
}

\author{
R. K. Meena ${ }^{1}$, S. S. Sharma ${ }^{2}$ and S. Singh ${ }^{3}$ \\ Department of Plant Pathology, RCA, MPUAT, Udaipur-313001 (Rajasthan), India
}

\begin{abstract}
All the five isolates of Alternaria alternata isolated from different agro climate zone of Rajasthan were tested for their variability in terms of cultural, conidial, pathogenic characteristics and toxin production. All the five isolates differed in cultural characters i.e. dark black colored and very fast mycelial growth with smooth margins $(90.00 \mathrm{~mm})$, light black with white at centre and fast growing $(80.00 \mathrm{~mm})$, dark brown and medium mycelium growth with smooth margins $(75.00 \mathrm{~mm})$, black colored, medium flat mycelial growth with smooth margins $(68.00 \mathrm{~mm})$ and white with slightly black in colour with slow mycelial growth $(65.00$ $\mathrm{mm}$ ) were observed in Aa-1, Aa-2, Aa- $3, \mathrm{Aa}-4$ and Aa-5 respectively. The variability in conidial morphology of five different isolates was simple, septate, pale to dark brown in colour, often geniculate with one conidial scar. In respect of pathogenic variability, showed significant variations in terms of disease intensity and incubation periods. The isolates Aa-1 was highly pathogenic on Isabgol cv. RI-89 under artificial inoculation conditions showing $52.12 \%$ disease intensity followed by Aa3 ,Aa-2, Aa-4 and Aa-5 isolates. The variability in toxin production was reflected in terms of time taken in inducing wilting symptoms of Isabgol cuttings. Isolate Aa-1 was highly toxic followed by isolates Aa-2, Aa-3, Aa-4 and Aa-5.
\end{abstract}

Key words: Alternaria alternata, Cultural, Spore Morphology, pathogenic, Toxin variability and Plantago ovata

\section{INTRODUCTION}

Isabgol, Plantago ovata, belongs to a large genus of herbs distributed mostly in the temperate regions and a few in the tropics. It comprises about 800 species, of

Corresponding author email: rajeshpatho@gmail.com

${ }^{1}$ Ph.D. Scholar, Department of Plant Pathology, RCA, MPUAT, Udaipur-313001 (Rajasthan) India

${ }^{2}$ Professor, Department of Plant Pathology, RCA, MPUAT, Udaipur-313001 (Rajasthan) India

${ }^{3}$ Ph.D. Scholar, Department of Plant Pathology, RCA, MPUAT, Udaipur-313001 (Rajasthan) India 
which 10-14 are natives of India. In India, it is mainly cultivated in Mehsana and Banaskantha districts of Gujarat and adjoining districts of Rajasthan and to a limited extent in Haryana. Presently, Rajasthan is a dominating state of Isabgol production. Isabgol is cultivated in about 2,27,705 hectares of land in Rajasthan with the production of 1,39,998 tons (Anon., 2009-10). Isabgol growing districts of Rajasthan are Jalore, Barmer, Jodhpur, Bikaner, Pali, Sirohi, Chittorgarh and Udaipur. Its seeds and husk are used in the indigenous medicine for many centuries. Seed is the important plant part which has medicinal values. The husk has the property of absorbing and retaining water and therefore it works as an anti-diarrhoea drug.

Mandal (2010) reported that a number of plant diseases like wilt (Fusarium oxysporum Schlechtemend snyd and Hnns.), damping off (Pythium ultimum Trow.), leaf blight (Alternaria alternata (Fr.) Keissler), downy mildews (Peronospora plantaginis Underwood, $P$ eronospora alta Fuckel and Pseudopernospora plantaginis) and powdery mildew (Erysiphe cichoracearum D.C.) blight (Alternaria) attack Isabgol. In recent years, the diseases become serious problem of the medicinal plant. It has been found that downy mildew infected the plants are more prone to be attacked by Alternaria alternata. It causes considerable damage every year and sometimes become very severe which results in total yield. The present investigations were conducted to find variability in Alternaria alternata (Kessler) causing leaf blight of Isabgol.

\section{MATERIAL AND METHODS}

\section{Isolation, Purification and Identification of $A$. alternata}

Five isolates of A. alternata were collected from five different Agro climate zones of Rajasthan i.e., R.C.A. farm (Udaipur), Kapasan (Chittorgarh), Mandore (Jodhpur), Sumerpur (Pali) and Keshwana (Jalore). On the basis of morphological, cultural and pathogenic characteristics, the isolates were identified as Alteraria alternata (Fr.) Keissler. Pathogenicity test was performed according Koch's postulates for all the five isolates. The identity of R.C.A. farm (Udaipur) isolate was confirmed by Indian Type Culture Collection (ITCC), Division of Plant Pathology, IARI, New Delhi-110012 (The ITCC Code no.6317, 2008).

\section{Cultural variability}

For cultural variability, five isolates of the pathogen were grown on potato dextrose agar (PDA) medium to record their growth pattern. The plates were inoculated with $5 \mathrm{~mm}$ discs cut from PDA culture of the isolates. The discs were placed at the centre of the Petri plates containing PDA. All inoculated plates were incubated at $25 \pm 1^{\circ} \mathrm{C}$ temperature in $\mathrm{BOD}$ incubator. Each isolate was replicated thrice (Petri dishes). The growth rate was measured and colony characters, pigmentation, growth habit and sporulation were recorded after $24 \mathrm{hrs}$ of incubation till the growth of the pathogen in Petri plate completes. 


\section{Variability in spore morphology}

Purified culture of each isolate was prepared following single spore method. For this purpose, a conidial suspension was prepared in sterilized distilled water from 10 days old culture on PDA and flooded on $2 \%$ plain agar in Petri plates. The excess suspension was drained off and the Petri plates were incubated in inverted position at $25 \pm 1^{0} \mathrm{C}$. After eight hours of incubation, a single germinating spore was marked with the help of dummy objective and then transferred individually with a piece of plane agar medium to PDA slants by inoculating needle under aseptic conditions. These monoconidial isolates were maintained on PDA slants and used to study spore morphology. Observations on variation in conidial dimension of five isolates of $A$. alternata were recorded with the help of Ocular and Stage Micrometer.

\section{Pathogenic variability}

Pathogenic variability is the genetic characters of fungi which may vary amongst isolates. Healthy seeds of Isabgol variety RI-89 were surface sterilized with $0.1 \% \mathrm{HgCl}_{2}$ and were sown in pot containing sterilized soil @ 10 seeds per pot and replicated thrice (three pots). Leaves, stems and branches of six weeks old Isabgol plants were randomly selected, and these were injured gently by delicate brush and ten days old culture suspensions of individual isolates were sprayed with an automizer in early morning, when dew deposition was observed on the leaves of the plants. Simultaneously, un-inoculated check was maintained by spraying sterilized distilled water on the plants. The inoculated plants were observed daily to record the incubation period for disease development. The disease intensity was calculated with the help of disease rating scale (1-5) where,

$1=1-20 \%$ infection or $1-20 \%$ leaves of the plant are infected, $2=21-40 \%$ infection or $1-40 \%$ leaves of the plant are infected, $3=41-60 \%$ infection or $41-60 \%$ leaves of the plant, $4=61-80 \%$ infection or $61-80 \%$ leaves of the plant are infected and $5=81-100 \%$ infection or $81-100 \%$ leaves of the plant are infected.

Per cent disease index (PDI) was calculated data following standard formula (Wheeler (1969), as given:

$$
\mathrm{PDI}=\frac{\sum 1 \mathrm{xn}+2 \mathrm{xn}+3 \mathrm{xn}+4 \mathrm{x} \mathrm{n}+5 \mathrm{xn}}{\mathrm{N}} \mathrm{X} \frac{100}{\text { Maximmum score (5) }}
$$

Where, $\mathrm{n}=$ Number of plants in each score

$\mathrm{N}=$ Total number of plants checked

\section{Toxin variability}

For determining toxin variability, $25 \mathrm{ml}$ Richards' medium having $\mathrm{pH} 6.5$ was poured in $100 \mathrm{ml}$ sterilized flasks were inoculated with $5 \mathrm{~mm}$ diameter fungal discs of 10 days old culture of different isolates of A. alternata grown on PDA and incubated at $25 \pm 1^{\circ} \mathrm{C}$ for 15 days. The culture filtrate was obtained by filtration through Whatman No.42 filter paper. The culture filtrates obtained from 15 days old 
cultures of A. alternata were centrifuged at $600 \mathrm{rpm}$ for $20 \mathrm{~min}$. The clear supernatant was collected in clean sterilized conical flasks and pellet sedimented at the bottom of the centrifuge tube was discarded. The clear supernatant solutions served as samples of crude toxin produced by different isolates were used to study toxin variability using detached (Salvik,1974).Observations were recorded regarding toxicity symptom expressions like necrosis, leaf drooping, wrinkling and drying of leaves at regular intervals of $6,12,18,20$ and $24 \mathrm{hrs}$.

\section{RESULTS AND DISCUSSION}

\section{Cultural variability}

Considerable variability in all five in terms of colony characters like dark black colourd and very fast mycelial growth with smooth margin, light black with white at centre and fast growing, dark brown and mycelial growth with smooth margin, black colored, flat mycelial growth with smooth margin, and white with slightly black in colored with slow mycelial growth were observed in Aa-1, Aa-2, Aa-3, Aa-4 and Aa5 respectively. The average radial growth of isolate Aa-1 was highest i.e. $90.00 \mathrm{~mm}$ while, in isolate Aa-2, Aa-3, Aa-4 and Aa-5, it was comparatively less i.e. $80.00 \mathrm{~mm}$, $75.00 \mathrm{~mm}, 68.00 \mathrm{~mm}$ and $65.00 \mathrm{~mm}$ respectively on $7^{\text {th }}$ day of incubation under uniform environments and medium. Sporulation was recorded in all five isolates but very good sporulation was observed in Aa-1. In view of the results obtained for cultural variation, it is clear that all the five isolates differed with respect to mycelial growth of A. alternata attained after $7^{\text {th }}$ day for sporulation and colony characters. (Table 1) The results are also in similarity with the results obtained by Verma et al. (2007), Raja and Reddy (2007) and Tetarwal et al. (2008).

\section{Variability in spore morphology}

Clear variations among the isolates of A. alternate was observed (Table 2) The spore characteristics of individual isolates are described below:

Aa-1: Conidia were simple, obclavate, pale to dark brown formed in chains. Conidia have both transverse and vertical septa measuring 23-31 x 14-19 $\mu \mathrm{m}$ (with beak) and 6-18 x 6-11 $\mu \mathrm{m}$ (without beak).

Aa-2: Conidia were light brown to dark brown, obclavate, measuring 22-28 x 13-16 $\mu \mathrm{m}$ (with beak) and 9-11 x 7-10 $\mu \mathrm{m}$ (without beak).

Aa-3: Conidia dark brown colored, long beak and both transverse and vertical septa were present. The size of conidia measuring 29-36 x 14-23 $\mu \mathrm{m}$ (with beak) and 7-21 x 8-11 $\mu \mathrm{m}$ (without beak).

Aa-4: Conidia obclavate, shorten beak and light brown to dark brown in colour measuring 20-24 x 14-17 $\mu \mathrm{m}$ (with beak) and 8-12 x 6-9 $\mu \mathrm{m}$ (without beak).

Aa-5: Conidia were light brown and measuring 18-31 x 12-22 $\mu \mathrm{m}$ (with beak) and 10-15 x 7-9 $\mu \mathrm{m}$ (without beak). 
The findings of the present investigation supported with the findings of Raja and Reddy (2007) collected the samples of leaf spot and fruit rot caused by Alternaria alternata from brinjal growing areas and it was found that The size of conidia varied from $35.2-43.5 \mu \mathrm{m}$ and 12.4-13.9 $\mu \mathrm{m}$ wide, with average beak length of 9.6 -12.4 $\mu \mathrm{m}$. Horizontal and vertical septations of conidia varied form 1.8 and 0.3 , respectively and conidia were produced in chain.

\section{Pathogenic variability}

The isolates of the pathogen collected from different geographical areas may show difference in virulence. The isolates Aa-1 was found to be highly pathogenic on Isabgol cv. RI-89 under artificial inoculation conditions, which showing 52.12\% disease intensity followed by Aa-3 (47.56\%), Aa-2 (41.40\%), Aa-4 (38.20\%) and Aa$5(35.48 \%)$. However, data were recorded 4-5 days of incubation in Aa-1 followed by Aa-3 (4-6), Aa-2 (4-6), Aa-4 (5-7) and Aa-5 (5-7). The seedlings grown applying sterilized distilled water without inoculation did not produce any blighted symptoms and grew healthy (Table 3 ). The pathogenic variability have also been carried out by Verma et al. (2007) and Kumar et al. (2008) on A. solani. They recorded pathogenic variability among different isolates of $A$. solani. Tetarwal et al. (2008) observed variability among six isolates of A. alternata infecting Senna (Cassia angustifolia)

\section{Toxin variability}

The details of the experimental results are presented in Table 4. The culture filtrate is assumed as 100 per cent toxin concentration. This was simply an indicator test for toxin production. The symptoms like drooping of leaves, blackening of leaves was initiated at 6 hours and continued up to twenty-four hours, finally leading to wilting and necrosis, thus revealing the existence of variation among the isolates in producing toxic metabolites in the culture medium, which was reflected in terms of inducing wilting of Isabgol cuttings. The results indicated that Aa-1 isolate showed very severe toxic effect where initial toxicity symptom expression was within six hours, leading to complete and severe necrosis of leaves with distinct black colourations. Similarly, severely toxic, moderately toxic, slight toxic and least toxic effect were observed in cultural filtrate toxin of Aa-2, Aa-3, Aa-4 and Aa-5 isolates, respectively. This suggests that the toxin has active role in causing disease as well as mortality. Such phytotoxic effects produced by culture filtrate were also reported by Reddy and Chaudhary (1990) where, they observed that, when pigeon pea seeds were soaked in culture filtrate of six Fusarium udum isolates for 6, 12, 24 h, no germination occurred after $24 \mathrm{~h}$ and radial length was also decreased with increasing in soaking time. Maiero et al. (1991) stated that A. solani produced phytotoxic metabolites, and tomato seedlings exposed to culture filtrates for $20 \mathrm{~h}$ exhibited marginal and inter veinal leaf necrosis and subsequently wilting. 


\section{ACKNOWLEDGMENT}

The authors are highly grateful to the Head, Department of Plant Pathology and Dean, Rajasthan College of Agriculture, Udaipur (Raj.) for providing necessary facilities and Project Director, AINP - M \& AP for financial support.

\section{REFERENCES}

Government of Rajasthan. 2009-10. District wise, area, production and yield of Rabi crops. Directorate of Agriculture, Government of Rajasthan. (www.rwjasthankrishi.gov.in, Retrieved on 21-09-2011)

Kumar, V., Haldar, S., Pandey, K.K., Singh, R.P., Singh A.K. and Singh, P.C. 2008. Cultural, morphological, pathogenic and molecular variability amongst tomato isolates of Alternaria solani in India. World Journal Microbiology and Biotechnology, 24:10031009

Maiero, M., Bean, G. A. and Ng, T. J. 1991. Toxin production by Alternaria solani and its related phytotoxicity to tomato breeding lines. Phytopathology, 81:1030-1033

Mandal, K. 2010. Disease of some important medicinal crops and their management. Microbial Diversity and Plant Disease management. VDM Verlag Dr. Muller, Germany, 509

Raja, P. and Reddy, A.V. Ramama. 2007. Morphological and biological variability of Alternaria spp. causing leaf spot and fruit rot of brinjal. Journal of Mycology and Plant Pathology, 37 (2): 336-338

Reddy, N.P.E. and Chaudhary, K.C.B. 1990. Effect of culture filtrates of Fusarium udum on the seeds on pigeon pea. Madras Agricultural Journal, 77 (2): 109-111

Salvik, B. 1974. Methods of studying plant water relations. Academia Publishing House of the Czechoslovak Academy of Sciences. pp-449

Tetarwal, M. L., Rai P.K. and Shekhawat, K.S. 2008. Morphological and pathogenic variability of Alternaria infecting senna. Journal of Mycology and Plant Pathology, 38 (2): $375-377$

Verma, P. K., Singh, S., and Gandhi, S.K. 2007. Variability among Alternaria solani isolates causing early blight of tomato. Indian Phytopathology, 60 (2): 180-186

Wheeler, B. E.J. 1969. An Introduction of Plant Diseases. John Willey and Sons Ltd. London. pp. 301 
Table 1: Cultural variability among five isolates of Alternaria alternata on PDA

\begin{tabular}{l|l|c|c|c|c}
\hline $\begin{array}{c}\text { Sl. } \\
\text { No. }\end{array}$ & Isolates & $\begin{array}{c}\text { Location of } \\
\text { collection of } \\
\text { isolates }\end{array}$ & $\begin{array}{c}\text { Radial } \\
\text { mycelial } \\
\text { growth } \\
\text { in (mm) }\end{array}$ & Sporulation & Colony characters \\
\hline 1. & Aa-1 & Udaipur & 90.00 & ++++ & $\begin{array}{l}\text { Dark black colourd, very fast } \\
\text { mycelial growth with smooth } \\
\text { margin. }\end{array}$ \\
2. Aa-2 & Chittorgargh & 80.00 & +++ & $\begin{array}{l}\text { Light black with white at } \\
\text { centre and fast growing. }\end{array}$ \\
3. Aa-3 & Jodhpur & 75.00 & +++ & $\begin{array}{l}\text { Dark brown and medium } \\
\text { mycelial growth with smooth } \\
\text { margin. }\end{array}$ \\
4. Aa-4 & Pali & 68.00 & ++ & $\begin{array}{l}\text { Black colourd, flat mycelial } \\
\text { growth with smooth margin. } \\
\text { White with slightly black in } \\
\text { colour and slow mycelial } \\
\text { growth. }\end{array}$ \\
5. Aa-5 & Jalore & 65.00 & ++ & \\
7 & & & \\
\hline
\end{tabular}

*Average of three replications

Note: $++=$ Fair, $+++=$ Good, $++++=$ very good.

Table 2: Variation in conidial morphology of five isolates of Alternaria alternata

\begin{tabular}{|c|c|c|c|c|c|c|c|c|c|}
\hline \multirow[t]{3}{*}{ S. No. } & \multirow[t]{3}{*}{ Isolates } & \multicolumn{4}{|c|}{$\begin{array}{l}\text { Conidial morphology with beak } \\
\qquad(\mu \mathrm{m})\end{array}$} & \multicolumn{4}{|c|}{$\begin{array}{l}\text { Conidial morphology without beak } \\
\qquad(\mu \mathrm{m})\end{array}$} \\
\hline & & \multicolumn{2}{|c|}{ Length } & \multicolumn{2}{|c|}{ Width } & \multicolumn{2}{|c|}{ Length } & \multicolumn{2}{|c|}{ Width } \\
\hline & & Mean & Range & Mean & Range & Mean & Range & Mean & Range \\
\hline 1. & Aa-1 & $28.05 \pm 1.68$ & $23-31$ & $17.18 \pm 1.00$ & $14-19$ & $12.93 \pm 1.76$ & $6-18$ & $8.73 \pm 0.69$ & $6-11$ \\
\hline 2. & Aa-2 & $24.84 \pm 1.26$ & $22-28$ & $15.23 \pm 0.76$ & $13-16$ & $10.22 \pm 0.51$ & $9-11$ & $8.47 \pm 0.42$ & $7-10$ \\
\hline 3.' & Aa-3 & $32.19 \pm 1.69$ & $29-36$ & $20.08 \pm 1.48$ & $14-23$ & $16.67 \pm 4.02$ & $7-21$ & $9.55 \pm 0.46$ & $8-11$ \\
\hline 4. & $\mathrm{Aa}-4$ & $22.22 \pm 0.99$ & $20-24$ & $15.23 \pm 0.76$ & $14-17$ & $9.30 \pm 0.72$ & $8-12$ & $7.88 \pm 0.44$ & $6-9$ \\
\hline \multirow[t]{4}{*}{5.} & Aa-5 & $28.01 \pm 2.90$ & $18-31$ & $18.95 \pm 1.91$ & $12-22$ & $12.07 \pm 1.00$ & $10-15$ & $8.43 \pm 0.44$ & $7-9$ \\
\hline & $\mathrm{SEm} \pm$ & \multicolumn{2}{|c|}{0.26} & \multicolumn{2}{|c|}{0.19} & \multicolumn{2}{|c|}{0.34} & \multicolumn{2}{|r|}{0.05} \\
\hline & \multicolumn{2}{|c|}{$\mathrm{CD}$ at $5 \%$} & 0.74 & \multicolumn{2}{|c|}{0.55} & \multicolumn{2}{|l|}{0.97} & \multicolumn{2}{|c|}{0.16} \\
\hline & $\mathrm{CV} \%$ & \multicolumn{2}{|c|}{9.80} & \multicolumn{2}{|c|}{11.35} & \multicolumn{2}{|l|}{8.40} & \multicolumn{2}{|c|}{6.84} \\
\hline
\end{tabular}

* Mean no. of 25 conidia and \pm S.D. of mean value 
Table 3: Pathogenic variability of five isolates Alternaria alternata under artificial inoculation conditions.

\begin{tabular}{c|c|c|c}
\hline S.No. & Isolates & Disease Intensity $(\boldsymbol{\%})$ & Incubation periods (days) $^{*}$ \\
\hline 1. & Aa-1 & $52.12(52.12)$ & $4-5$ days \\
2. & Aa-2 & $41.40(41.39)$ & $4-6$ days \\
3. & Aa-3 & $47.56(47.56)$ & $4-6$ days \\
4. & Aa-4 & $38.20(38.19)$ & $5-7$ days \\
5. & Aa-5 & $35.48(35.48)$ & $5-7$ days \\
6. & Spray with water & $0.00(0.00)$ & - \\
& (Control) & 0.569 & \\
\hline \multicolumn{5}{r}{ SEm \pm} & 1.792 & \\
& CD at 5\% & 2.41 & \\
& CV\% &
\end{tabular}

*Average of three replications

Figures in parentheses are angular transformed values

Table 4: Toxin variability among five isolates based on their culture filtrates (crude toxin) toxicity symptoms on Isabgol leaves.

\begin{tabular}{|c|c|c|c|}
\hline S.No. & Isolates & Toxicity symptoms observed & Grade \\
\hline 1. & $\begin{array}{l}\text { Un-inoculated } \\
\text { broth }\end{array}$ & Did not show any toxicity. & Non toxic \\
\hline 2. & Aa-1 & $\begin{array}{l}\text { Initial toxicity symptom expression in six } \\
\text { hours, leading to complete and severe necrosis } \\
\text { of leaves with distinct black colourations. }\end{array}$ & $\begin{array}{l}\text { Very } \\
\text { Severely } \\
\text { Toxic }\end{array}$ \\
\hline 3. & Aa-2 & $\begin{array}{l}\text { Initial toxicity symptom expression in twelve } \\
\text { hours, leading to complete leaf drooping, } \\
\text { wrinkling, drying and brittling of leaves. }\end{array}$ & $\begin{array}{l}\text { Severely } \\
\text { Toxic }\end{array}$ \\
\hline 4. & Aa-3 & $\begin{array}{l}\text { Initial toxicity symptoms expression in } \\
\text { eighteen hours, leading to complete wrinkling } \\
\text { and necrosis. }\end{array}$ & $\begin{array}{l}\text { Moderately } \\
\text { Toxic }\end{array}$ \\
\hline 5. & $\mathrm{Aa}-4$ & $\begin{array}{l}\text { Initial toxicity symptoms expression in twenty } \\
\text { hours, leading to slight necrosis. }\end{array}$ & Slight Toxic \\
\hline 6. & Aa-5 & $\begin{array}{l}\text { Initial toxicity symptoms expression after } \\
\text { twenty-four hours, leading to least toxic. }\end{array}$ & Least toxic \\
\hline
\end{tabular}

